\title{
CHARACTERIZATION OF IN-SITU BN INTERFACE FORMED BY NITRIDATION OF NEXTEL 312
}

Frances I. Hurwitz, NASA Lewis Research Center, Cleveland, OH 44135

John Riehl and John Madsen, Northrop Grumman Corp., Bethpage, NY 11714

Terry R. McCue, Dynacs Engineering Co., Inc., Brookpark, OH 44142

Darwin L. Boyd, Kent State University, Kent, OH 44242

\begin{abstract}
Treatment of Nextel ${ }^{\mathrm{TM}} 312$ in a reactive environment has been used as a low cost approach to the formation of BN on the fiber surface. Although the BN enriched surface region is extremely thin $(<40 \mathrm{~nm})$, it is effective in providing debonding and composite behavior. Variation in mechanical behavior of Nextel ${ }^{\mathrm{TM}}$ 312/BN/Blackglas ${ }^{\text {TM }}$ composites has been noted among panels fabricated with AF10 cloth treated in different nitridation runs. Understanding this variation became the rationale for undertaking a detailed characterization of the nitrided fiber using field emission scanning electron microscopy, low voltage energy dispersive $\mathrm{x}$-ray and Auger electron spectroscopy. Chemical composition and surface morphology are discussed in relation to observed mechanical behavior of Nextel ${ }^{\mathrm{TM}}$ 312/Blackglas ${ }^{\mathrm{TM}}$ composites tested in bending.
\end{abstract}

\section{INTRODUCTION}

The focus of the Low Cost Ceramic Composites $\left(\mathrm{LC}^{3}\right)$ program is to develop a framework for fabricating low-cost, structural ceramic matrix composite (CMC) components having potential for high temperature operation and high specific properties in oxidizing environments. The approach is to introduce low cost materials and process technologies to reduce CMC manufacturing cost and at the same time enhance component lifetimes.

The program has selected Nextel ${ }^{\mathrm{TM}} 312$ fiber for its relatively low cost and ability to form an in-situ BN interface, thus eliminating the need for CVI deposition of an interface coating. The Blackglas ${ }^{\mathrm{TM}}$ polymer system was chosen for its relatively low cost and amenability to resin transfer molding (RTM) and resin vacuum infiltration (RVI) processing, and needed temperature capabilities. 
Blackglas ${ }^{\mathrm{TM}}$ undergoes significant shrinkage on pyrolysis, as do all preceramic polymers, resulting in the need for a number of reinfiltration cycles to process the composite to a desired matrix density and optimize mechanical properties. The resulting matrix is highly microcracked. ${ }^{1}$

Nextel ${ }^{\mathrm{TM}} 312$ ceramic fiber ( $3 \mathrm{M}$ ) has the nominal composition $62 \% \mathrm{Al}_{2} \mathrm{O}_{3}, 14 \%$ $\mathrm{B}_{2} \mathrm{O}_{3}, 24 \% \mathrm{SiO}_{2}$. Processes for forming a $\mathrm{BN}$ enriched surface on this fiber by heat treatment in an ammonia containing atmosphere have been reported in the literature, ${ }^{2-4}$ and the $i n-s i t u \mathrm{BN}$ has been characterized by transmission electron microscopy (TEM) and $x$-ray photoelectron spectroscopy (XPS) $)^{5,6}$, as well as by secondary ion mass spectrometry (SIMS). 7,8

The depth of boron enrichment and nitrogen incorporation near the fiber surface is quite small, on the order of $20-30 \mathrm{~nm}$, with maximum boron levels observed at about $5 \mathrm{~nm}$ from the surface. Reaction is presumed to occur by diffusion of ammonia into the fiber, to react with $\mathrm{B}_{2} \mathrm{O}_{3}$, forming $\mathrm{BN}$, with loss of $\mathrm{H}_{2} \mathrm{O}$. Loss of $\mathrm{SiO}$ from the fiber might be taking place as well. ${ }^{7}$ Although the surface enrichment is extremely thin, desirable interface properties are shown to be produced when treated fiber is incorporated into Blackglas ${ }^{\mathrm{TM}}$ matrix composites. ${ }^{4}$ It also has been shown that the interphase does not react with the matrix on oxidative exposure of the composite at $600^{\circ} \mathrm{C}$ for up to 1000 hours. ${ }^{6}$

We have noted a larger variation in mechanical properties of composites manufactured from fabric nitrided in different runs than among panels produced from cloth from the same nitridation run; and therefore selected panels and samples of fabric from three different runs were chosen for comparison.

\section{EXPERIMENTAL}

Nextel ${ }^{\mathrm{TM}} 312$ AF-10 fabric (3M) was cleaned by heating in air to remove fabric sizing, then treated in an $\mathrm{NH}_{3} / \mathrm{H}_{2}$ atmosphere by Allied Signal to produce a $\mathrm{BN}$ enriched fiber surface. Panels were fabricated using fabric produced in three different nitridation runs.

Ten ply composite panels having a fiber volume fraction of 0.5 were prepared from the nitrided AF-10 five harness satin weave fabric and Blackglas 493 resin and catalyst (Allied Signal) using resin transfer molding, curing, pyrolysis and reinfiltration cycles. The resin was degassed and injected into the tooled, stacked plies along their length using a constant volume injection system (Liquid Control). The long edges of the panel parallel to the flow direction are sealed to prevent race tracking of the resin along the panel edges during the fill. The panel was compressed to a thickness of $1.9 \mathrm{~mm}$ to maintain fiber volume fraction. Pyrolysis was carried out in an Inconel 718 retort at a heating rate of $2^{\circ} \mathrm{C} / \mathrm{min}$ to a final 
temperature of $1000^{\circ} \mathrm{C}$, with a 1 hour hold at that temperature. Pyrolysis runs were performed in high purity argon (99.995\%) at approximately $1 \mathrm{~atm}$ with a flow rate of $0.056-0.112 \mathrm{~cm}^{3} / \mathrm{h}$. This procedure permitted a complete exchange of gas in the retort every $15 \mathrm{~min}$. A total of 5 reinfiltraton cycles were used.

Composite mechanical behavior was characterized by three point flexural testing for comparison with prior data, utilizing a sample geometry of $7.62 \mathrm{x}$ $0.635 \mathrm{~cm}$, using a supporting span of $5.08 \mathrm{~cm}$. Testing was at a constant displacement loading rate of $0.127 \mathrm{~cm} / \mathrm{min}$. Load versus displacement was measured and recorded and from it values of peak stress, modulus and percent strain (at peak load) were calculated.

Pieces of nitrided Nextel ${ }^{\mathrm{TM}} 312$ cloth were characterized using field emission scanning electron microscopy (Hitachi 4700), low voltage energy dispersive spectroscopy (1-3 kV), Auger spectroscopy (AES) and x-ray diffraction analysis.

\section{RESULTS AND DISCUSSION}

Three nitridation runs of AF-10 were performed by Allied Signal, Inc., and are designated as Runs 50,62 and 67. Flexural properties of composite samples using fabric from each of these runs is summarized in Figure 1. Significant differences in flexural strength were observed from among the panels, with Panel

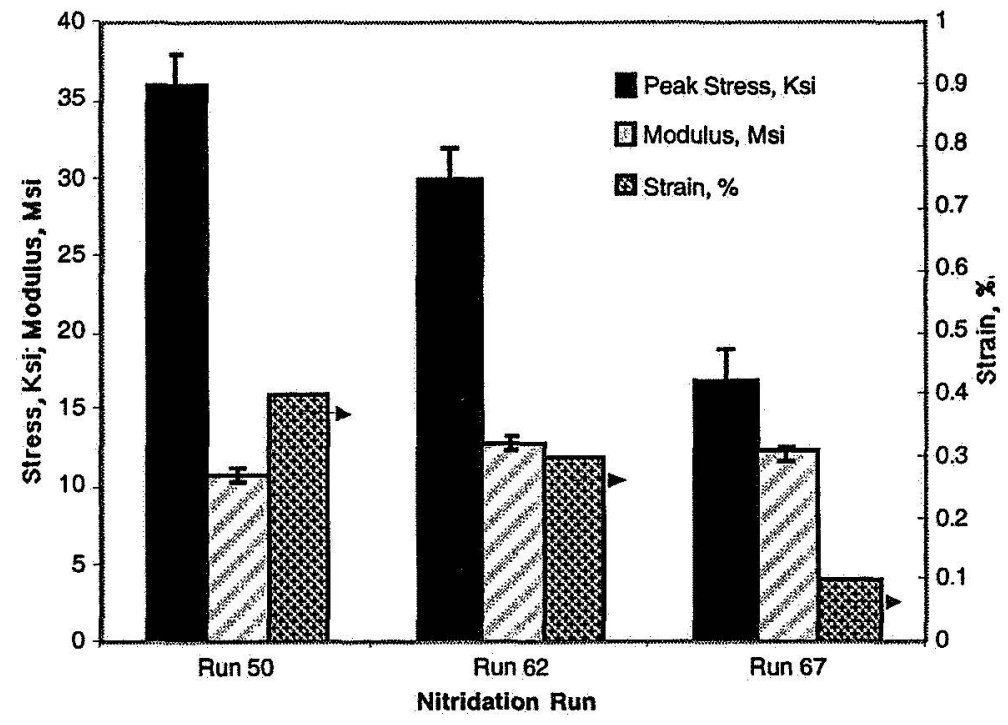

Figure 1: Flexural properties of Nextel $^{\mathrm{TM}}$ Blackglas $^{\mathrm{TM}}$ composites 
50 having the highest strength, followed by Panels 62 and 67 . Strain to failure showed the same decreasing trend across the group of three, while modulus was slightly lower for Panel 50 compared with 62 and 67.

SEM analysis of small pieces of fabric sampled from the three nitridation runs revealed differences in surface texture of the fibers (Figure 2). A piece of fabric which had been heat cleaned but not nitrided was examined for comparison. The
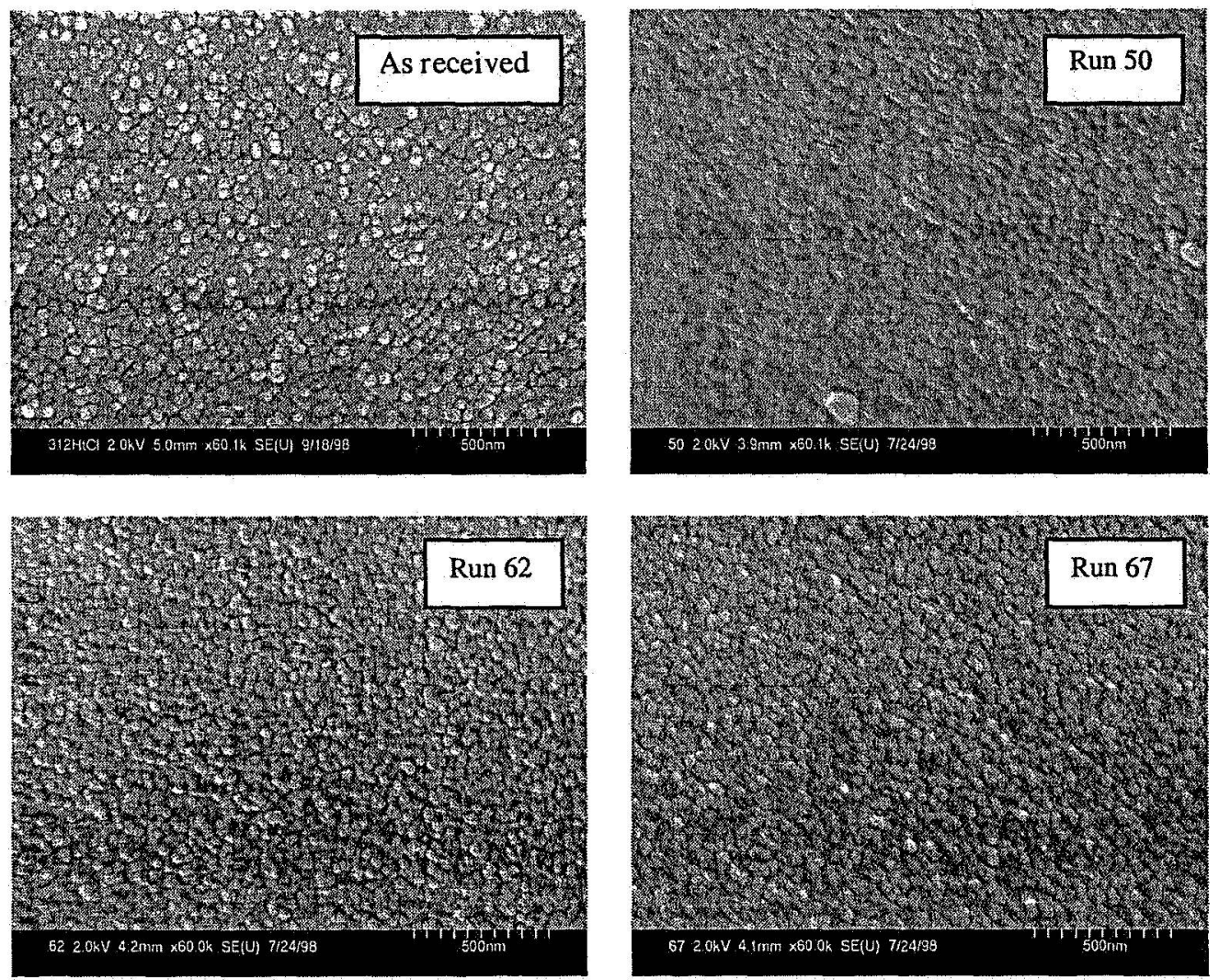

Figure 2: Surface texture of heat cleaned and nitrided fiber

as heat cleaned fiber exhibited a rough, granular texture, which varied in degree of surface roughness among the nitrided samples, with runs 62 and 67 being slightly smoother than the control sample, and run 50 showing the least surface roughness.

Energy dispersive spectroscopy (EDS) at $1 \mathrm{kV}$ minimizes beam penetration and fails to excite heavier elements, increasing the relative signal from light elements and surface sensitivity. This revealed variation in relative peak heights of $B, C, N$ and $O$ among the cloth samples, with Sample 50 showing the largest relative concentrations of $\mathrm{B}$ and $\mathrm{N}$. At $3 \mathrm{kV}$ there is both increased beam 
penetration and excitation of heavier elements, so that and $\mathrm{Al}$ and Si peaks are observed as well. Comparison of $\mathrm{B}$ and $\mathrm{N}$ intensities with the $\mathrm{Al}$ peak again shows the highest $\mathrm{BN}$ concentration in Run 50, with decreasing levels in 62 and 67, respectively (Figure 3).
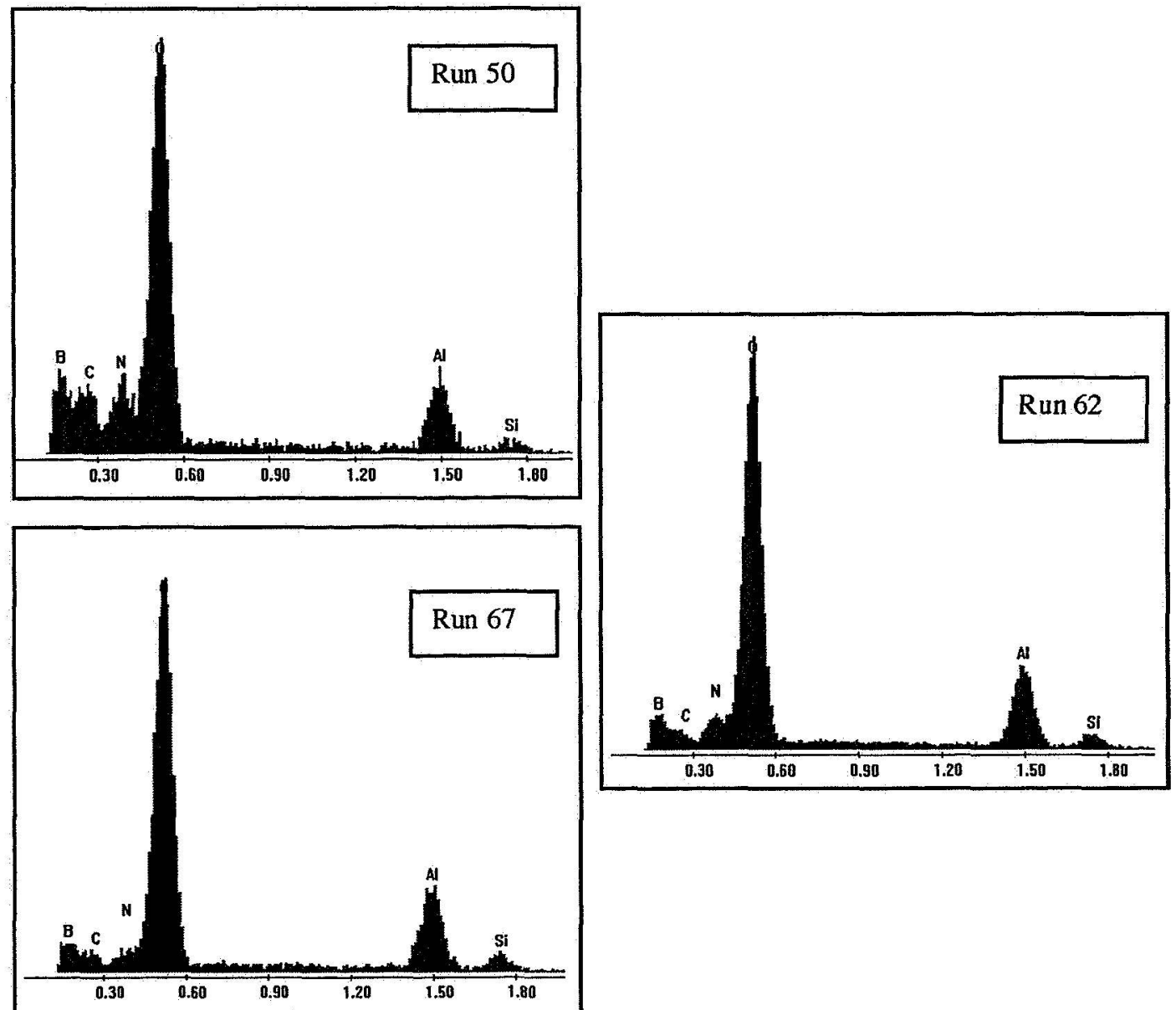

Figure 3: Energy dispersive spectra of nitrided fabric, $3 \mathrm{kV}$.

Auger spectroscopy shows incorporation of $\mathrm{N}$ to a depth of $30-35 \mathrm{~nm}$ in Run 50, $25 \mathrm{~nm}$ in Run 62, and 15-20 nm in Run 67 (Figure 4). B enrichment at the surface is nominally 50 atomic percent in Run 50,45 and 30 percent, respectively, in Runs 62 and 67. In Run 67, bulk fiber composition is reached at only $15 \mathrm{~nm}$. The Auger results corroborate the EDS finding of greatest $\mathrm{N}$ incorporation and highest surfaceBN in Run 50. 

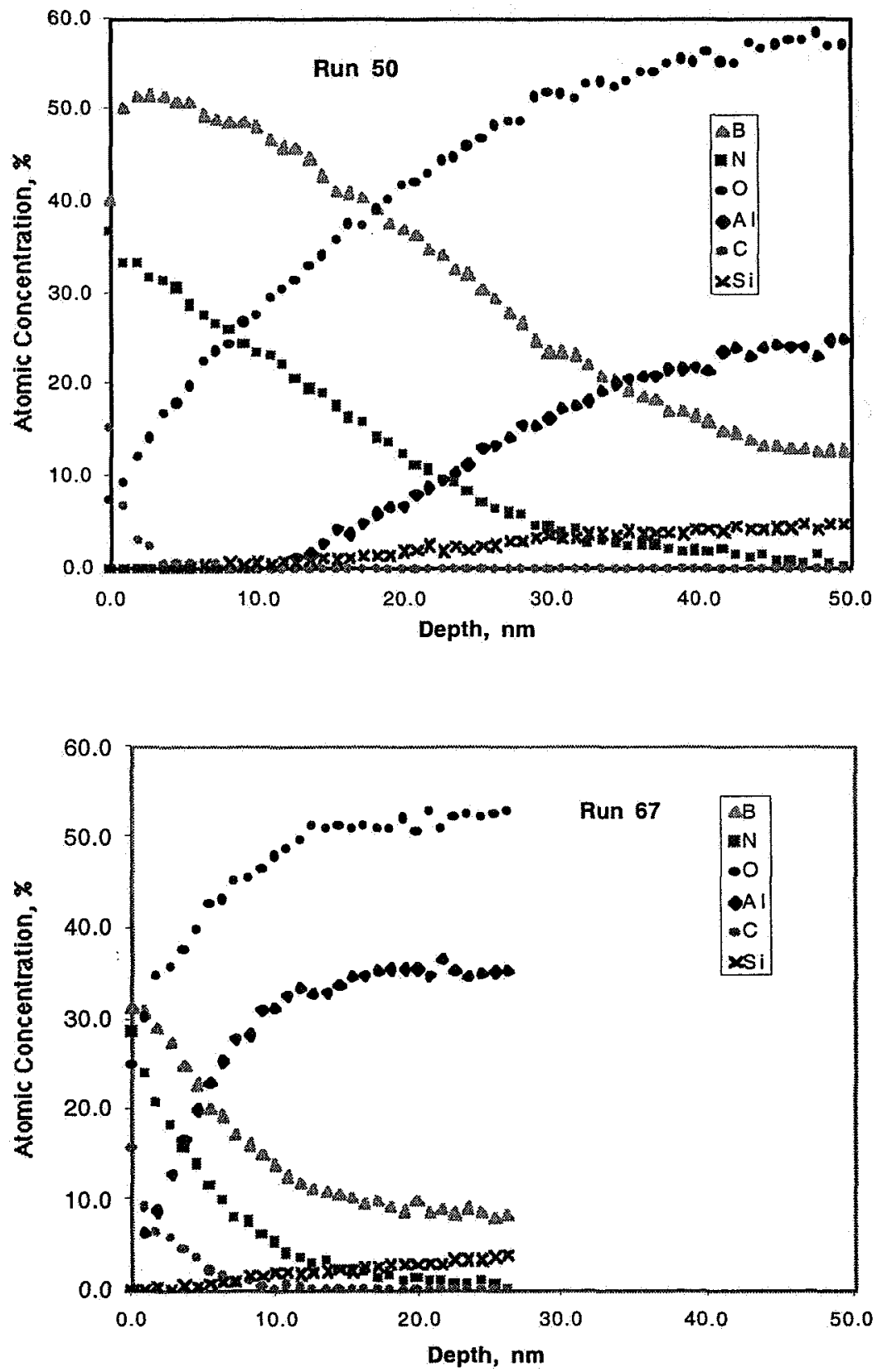

Figure 4: AES depth profile of nitrided fabric. 
Based on the EDS and Auger data, a coating "thickness" is difficult to define, because the nitridation treatment provides a change in surface chemistry of the fiber, rather than an actual "BN" coating layer. This interpretation is supported by the published TEM data. ${ }^{6}$

$\mathrm{X}$-ray diffraction analysis was performed on ground fiber samples to identify crystalline phases. The as heat cleaned AF-10 fiber was totally amorphous, whereas all nitrided samples showed the presence of $\mathrm{Al}_{11} \mathrm{~B}_{4} \mathrm{O}_{33}$. Relative concentrations of aluminum borate and crystallite size were indistinguishable among the three samples. Crystallization is attributed to temperature exposure during the nitridation treatment.

Improved composite performance, expressed as maximum flexural strength, is seen to coincide with a smoothing, or erosion, of the fiber surface roughness, which would enhance fiber sliding, as well as a change in fiber surface chemistry. The study does not permit separation of the two effects.

\section{SUMMARY AND CONCLUSIONS}

Nitridation of Nextel ${ }^{\mathrm{TM}} 312$ by heat treatment in ammonia alters the fiber surface chemistry and morphology, decreasing surface roughness as compared with the as heat cleaned fiber. Changes in surface chemistry are very localized, and alter the fiber to a depth of not more than $35-40 \mathrm{~nm}$ below its surface. Improvement in composite properties may be attributed to a decrease in surface roughness and/or altered bonding between fiber and matrix resulting from a change in surface chemistry. The large effect on flexural strength with fairly subtle variation in extent of nitridation suggests the need for close control of nitridation parameters. It is not possible to ascertain from this study if there is an effect of variation in extent of nitridation with position within a fabric roll, as the nitridation is carried out with loosely rolled fabric placed within a furnace.

\section{ACKNOWLEDGMENTS}

The authors wish to thank Ralph Garlick of NASA Lewis Research Center for $x$-ray diffraction analysis, and Dr. Donald Wheeler for Auger spectroscopy. This work was partially supported by DARPA Technology Development Agreement No. MDA972-93-2-0007 that is being administered by the Materials and Manufacturing Directorate of the Air Force Research Laboratory. 


\section{REFERENCES}

1. R. H. Stawovy, S. L. Kampe, W. A. Curtin, "Mechanical behavior of glass and Blackglas $^{\text {TM }}$ ceramic matrix composites," Acta Mater. 45, 5317-5325 (1997).

2. F. Simpson, J. Verzemnieks, Patent US 4,605,588, August 12, 1986.

3. F. Simpson, J. Verzemnieks, Patent US 4,948,662, August 14, 1990.

4. S. S. Campbell, S. T. Gonczy, "In-situ formation of boron nitride interfaces on Nextel $^{\mathrm{TM}} 312$ continuous ceramic fiber. I: Nitriding process and Blackglas ${ }^{\mathrm{TM}}$ ceramic matrix composite properties," Ceram. Eng. Sci. Proc. 15, 327-336 (1994).

5. N. R. Kasgiwale, et al., "Characterization of $\mathrm{BN}$ rich layer on ammonia treated Nextel $^{\mathrm{TM}} 312$ fibers," Mat. Res. Soc. Symp. Proc. 365, 389-394 (1995).

6. N. R. Kasgiwale, et al., "Evaluation of ammonia treated Nextel ${ }^{\mathrm{TM}} 312$ fiberBlackglas $^{\text {TM }}$ matrix composites," Ceram. Eng. Sci. Proc. 16, 621-631 (1995).

7. E. A. Leone, S. S. Campbell, "The use of secondary ion mass spectroscopy (SIMS) in the analysis of alumina-boria-silica ceramic," Ceram. Eng. Sci. Proc. 18, 381-389 (1997).

8. S. Campbell, E. Leone, M. McNallan, "The effect of processing parameters on the surface nitridation of Nextel ${ }^{\mathrm{TM}} 312$ ceramic," Ceram. Eng. Sci. Proc. 18, 391398 (1997). 